\title{
A study of the prevalence of respiratory morbidity and ventilatory obstruction in beauty parlour workers
}

\begin{abstract}
A study was conducted in beauty parlor workers of Lucknow, India, to assess the prevalence of respiratory morbidity and lung function abnormalities compared to their control subjects belonging to the same socioeconomic status and ethnic group, having never been exposed to the workplace of beauty parlor and having not used any cosmetics. Respiratory morbidity and bronchial obstruction based on PEFR study was conducted in 196 beauty parlor workers and 35 control subjects. All the participants were non-smokers and were matched for age, height, weight and socioeconomic status. Peak expiratory flow rate were performed using Peak Flow meter. Symptomatic workers showed bronchial obstruction (28\%), and this prevalence was significantly higher $(P<0.01)$ when compared to $6.7 \%$ among asymptomatic workers. Bronchial obstruction among female workers $(17.9 \%)$ was more prevalent $(P<0.01)$ than male workers (1.42). Overall respiratory morbidity among beauty parlor workers showed higher $(12.7 \%)$ when compared with control group (2.8\%) but differences couldn't attain any significance. Although nonsignificant, workers in beauty parlor showed more prevalence $(9.4 \%)$ of bronchial obstruction based on PEFR than controls (4\%). This study showed that beauty parlor workers were more prone to respiratory morbidity and lung function abnormalities, as the study group selected were nonsmokers.
\end{abstract}

Key words: Beauty parlor workers, PEFR, respiratory morbidity

\section{INTRODUCTION}

Occupational diseases are caused by a pathological response of the patients to their working environment. ${ }^{[1]}$ The type of work and duration of exposure influences respiratory morbidity among workers. ${ }^{[2]}$ Cosmetic use in the form of deodorant, shampoo, skin lotion, nail polish, hair dye, aftershave lotions, hair bleaching agents, perm liquids and hair spray are very common in beauty parlors. Hair dressers are exposed to many chemicals found in hair sprays, setting agents, hair coloring, hair lacquers, henna and permanent-wave solutions, which can potentially affect respiratory health but the etiological agents are uncertain. ${ }^{[3,4]}$

Earlier studies have reported a variety of clinical manifestations including lung cancer among female cosmetologists, ${ }^{[5]}$ malignant neoplasms and all lymphatic and hemopoetic cancers among black and white hair dressers. ${ }^{[6]} \mathrm{A}$ risk of developing lung cancer was found among beauticians and other female workers. ${ }^{[7]}$ Exposure to permanentwave solutions in a laboratory setting caused clinical symptoms and significant laboratory evidence of nasal airway obstruction. ${ }^{[8]}$ Polyvinylpyrrolidone in hair lacquers has been suspected of causing alveolitis and lung granulomatosis (thesaurosis) ${ }^{[9]}$ Another study has shown a weak association between cosmetic-associated respiratory problems. ${ }^{[10,11]}$

In occupational respiratory disease, spirometry is one of the most important diagnostic tools. It is the most widely used and most basic effort-dependent pulmonary function test and can measure the effects of restriction or obstruction on lung function. ${ }^{[12]}$ Periodic re-testing of workers can detect pulmonary disease in its earliest stages when corrective measures are more likely to be beneficial. Such intervention will improve the industrial hygiene, job transfer and medical treatment. In addition, pulmonary function testing (PFT) has assumed a key role in
C. Kesavachandran, S. K. Rastogi,

N. Mathur, V. Bihari, A. Singh

Epidemiology section Industrial Toxicology

Research Centre

(ITRC), Council of

Scientific \& Industrial Research (Govt. of

India) Lucknow, India

For correspondence: SK Rastogi,

Deputy Director and

Head, Epidemiology

Section, Industrial

Toxicology Research

Centre (ITRC), PB

No.80, MG Marg,

Lucknow-226001,

India. E-mail:

subhodhrastogi@

rediffmail.com

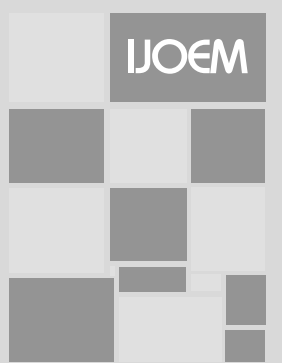


epidemiological studies investigating the incidence, natural history and causality of occupational and environmental respiratory disease. ${ }^{[13]}$

Most of the reports available are associated with hair dressers and cosmetologists. Limited knowledge is available on respiratory health of beauty parlor workers. The present study was designed to investigate the prevalence of respiratory morbidity and lung function abnormalities in beauty parlor workers. Such knowledge will be significant in preventing occupational health problems in these workplaces.

\section{MATERIALS AND METHODS}

\section{Selection of subjects}

A detailed history was taken to determine whether they would be included in the study or not on the basis of the exclusion criteria. They were questioned with regard to smoking cigarettes, other tobacco products, chewing tobacco or betel nut products. Addictions for the last five years were excluded from the study. After the initial interviews, 196 male and female non-smoking workers of beauty parlor from the city limits of Lucknow, India, were selected. Most of the workers (51.02\%) were exposed to beauty parlor for a period of $1-5$ years. A control group of 35 non-smoking subjects (non-beauty parlor workers like shopkeepers and office staff who were not using cosmetics and who had never visited beauty parlors) were selected from the same location having similar age group and socioeconomic status to compare the respiratory status of workers in beauty parlors. Beauty parlor workers were engaged in face massage, body massage, head massage, bleaching, facial, aromatherapy, hair treatment, pimples treatment, bridal makeup, dandruff treatment, skin treatment, hair coloring, herbal coloring, herbal henna hair dye, steam bath, mehandi and hair removal. Working hours of beauty parlor workers were from 10:30 to 20:00 for all week days, without using any self-protective measures.

\section{Assessment of respiratory health}

We developed a new questionnaire that was based on British Medical Research Council (BMRC), the National Heart, Lung and Blood Institute (NHLBI-USA), and the American Thoracic Society (ATS) Questionnaire. ${ }^{[14]}$ Our purpose was to identify cough, chest tightness, wheezing, dyspnea and asthma among the subjects. Physical examination of respiratory health of workers and control group were conducted in accordance with recommendations outlined in the Declaration of Helsinki.

\section{Spirometry}

Lung function tests - PEFR (Peak Expiratory Flow Rate) of workers and control group were performed using Peak Flow meter (Clement Clarke, UK). Total sample size for PEFR study was limited to 148 due to limitations of poor performance of the test by the workers. All the pulmonary function tests were carried out at a fixed time of the day (10:30 to 13:00). The apparatus was calibrated daily and operated within the ambient temperature range of $20-25^{\circ} \mathrm{C}$. The precise techniques in executing various lung function tests for the present study were based on the operation manual of the instrument with special reference to the official statement of the American Thoracic Society of Standardization of Spirometry. ${ }^{[15]}$ After taking a detailed history and anthropometric data, the subjects were informed about the whole maneuver. The subjects were encouraged to practice this maneuver before doing the pulmonary function test. The test was performed with subjects in standing position without nose clip. The test was repeated three times after adequate rest, and the results obtained were informed to the subjects. We defined the criteria for mild, moderate and severe on the basis of PEFR\% calculated by dividing the observed PEFR of the workers with the predicted PEFR for industrial workers. ${ }^{[16]}$ If the PEFR\% is between 70 and $80 \%$, obstruction is considered mild $_{i} 60-70 \%$ - moderate; and $<60 \%$ - severe. Total sample size for PEFR study was limited to 148 due to the poor performance of the test by the workers.

\section{Statistical analysis}

Significance of mean physical characteristic parameters (age, height and weight) and lung function parameters (PEFR) between exposed and controls were tested using Student's t test after ascertaining the homogeneity of variance. Prevalence of various respiratory impairments observed in the workers were compared to their controls, between male and female workers, between symptomatic and asymptomatic workers and were statistically compared using chi-square test.

\section{RESULTS}

\section{Physical characteristics}

Physical characteristics of workers in beauty parlor and control group were age (year) $33.2 \pm 8.1$ and $31.7 \pm 10.4$; height (cm) $157.9 \pm 9.4,155 \pm 7.2(P<0.05)$; and weight $(\mathrm{kg}) 60 \pm 12.2$ and 51.23 $\pm 9.2(P<0.05)$. The average height and weight of beauty parlor workers was significantly lower $(P<0.05)$ when compared to controls [Table 1].

\section{Respiratory morbidity}

Overall respiratory morbidity among beauty parlor workers

Table 1: Anthropometric data of workers in beauty parlours and controls

\begin{tabular}{lccc}
\hline Parameters & $\begin{array}{c}\text { Controls } \\
(\mathbf{n = 3 5 )} \\
\text { Mean } \pm \text { SD }\end{array}$ & $\begin{array}{c}\text { Workers } \\
(\mathbf{n = 1 9 6 )} \\
\text { Mean } \pm \text { SD }\end{array}$ & P value \\
\hline Age (yr) & $33.2 \pm 8.1$ & $31.7 \pm 10.4$ & $\mathrm{NS}$ \\
Height $(\mathrm{cms})$ & $157.9 \pm 9.4$ & $155 \pm 7.2$ & $P<0.05$ \\
Weight $(\mathrm{Kg})$ & $60 \pm 12.2$ & $51.23 \pm 9.2$ & $P<0.05$ \\
\hline
\end{tabular}

NS- Non significant 
was $12.7 \%$ when compared with control group (2.8\%) but differences couldn't attain any significance [Table 2]. Chief respiratory symptoms observed among the male workers were cough (10.3\%), chest tightness (2.06\%), wheezing (2.06\%) and asthma (1.03\%). Chief respiratory symptoms observed among the female workers were cough $(4.04 \%)$, chest tightness (3.03\%), wheezing (1.01\%), asthma (1.01\%) and dyspnea (1.01\%). Male workers (15.46\%) showed greater respiratory morbidity than female workers (10.10\%), although not significant [Table 3].

\section{PEFR}

Mean PEFR (L/min) of controls was $400.8( \pm 86.4)$, and in workers it was $374.6( \pm 63.1)$. Although nonsignificant, workers in beauty parlor showed greater prevalence (9.4\%) of bronchial obstruction based on PEFR than controls (4\%) [Table 4]. Symptomatic workers showed bronchial obstruction (28\%), and this prevalence was significantly higher $(P<0.01)$ when compared to $6.7 \%$ among asymptomatic workers [Table 5]. Bronchial obstruction among female workers (17.9\%) was more prevalent $(P<0.01)$ than male workers (1.42) [Table 6].

Table 2: Prevalence of respiratory morbidity in beauty parlour workers and controls

\begin{tabular}{|c|c|c|c|c|c|}
\hline \multirow[t]{2}{*}{ Symptoms } & \multicolumn{2}{|c|}{$\begin{array}{l}\text { Controls } \\
(n=35)\end{array}$} & \multicolumn{2}{|c|}{$\begin{array}{c}\text { Workers } \\
(n=196)\end{array}$} & \multirow[t]{2}{*}{$P$ value } \\
\hline & $\mathrm{n}$ & $\%$ & n & $\%$ & \\
\hline Cough & - & - & 14 & 7.1 & NS \\
\hline Chest Tightness & - & - & 5 & 2.5 & NS \\
\hline Wheezing & - & - & 3 & 1.5 & NS \\
\hline Asthma & - & - & 2 & 1.1 & NS \\
\hline Dyspnoea & 1 & 2.8 & 1 & 0.5 & NS \\
\hline Overall & 1 & 2.8 & 25 & 12.7 & NS \\
\hline
\end{tabular}

NS- Non significant

Table 3: Sex wise prevalence rate of respiratory morbidity among workers in beauty parlour workers

\begin{tabular}{lcccccc}
\hline Symptoms & \multicolumn{2}{c}{$\begin{array}{c}\text { Male } \\
(\mathbf{n = 9 7 )}\end{array}$} & & \multicolumn{2}{c}{$\begin{array}{c}\text { Female } \\
(\mathbf{n = 9 9 )}\end{array}$} & $P$ value \\
\cline { 2 - 3 } & $\mathbf{n}$ & $\%$ & & $\mathbf{n}$ & $\%$ & \\
\hline Cough & 10 & 10.30 & & 4 & 4.04 & NS \\
Chest tightness & 2 & 2.06 & & 3 & 3.03 & NS \\
Wheezing & 2 & 2.06 & & 1 & 1.01 & NS \\
Asthma & 1 & 1.03 & & 1 & 1.01 & NS \\
Dyspnoea & 0 & 0 & & 1 & 1.01 & NS \\
Overall & 15 & 15.46 & & 10 & 10.10 & NS \\
\hline
\end{tabular}

NS- Non significant

Table 4: Prevalence of bronchial obstruction based on PEFR among beauty parlor workers and controls

\begin{tabular}{|c|c|c|c|c|c|}
\hline \multirow[t]{2}{*}{ Parameter } & \multicolumn{2}{|c|}{$\begin{array}{l}\text { Control } \\
(n=25)\end{array}$} & \multicolumn{2}{|c|}{$\begin{array}{l}\text { Workers } \\
(n=148)\end{array}$} & \multirow[t]{2}{*}{$P$ value } \\
\hline & $n$ & $\%$ & $\mathbf{n}$ & $\%$ & \\
\hline Normal & 24 & 96 & 134 & 90 & NS \\
\hline Mild & 1 & 4 & 13 & 8.8 & NS \\
\hline Moderate & - & - & 1 & 0.6 & NS \\
\hline Overall obstruction & 1 & 4 & 14 & 9.4 & NS \\
\hline
\end{tabular}

NS- Non significant
Table 5: Prevalence of bronchial obstruction among symptomatic and asymptomatic beauty parlour workers based on PEFR

\begin{tabular}{|c|c|c|c|c|c|}
\hline \multirow[t]{2}{*}{ Parameter } & \multicolumn{2}{|c|}{$\begin{array}{c}\text { Symptomatic } \\
(n=25)\end{array}$} & \multicolumn{2}{|c|}{$\begin{array}{c}\text { Asymptomatic } \\
\quad(\mathrm{n}=171)\end{array}$} & \multirow[t]{2}{*}{$P$ value } \\
\hline & n & $\%$ & $\mathbf{n}$ & $\%$ & \\
\hline Normal & 18 & 72 & 116 & 67.8 & NS \\
\hline Mild & 6 & 24 & 8 & 4.67 & NS \\
\hline Moderate & 1 & 4 & 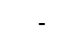 & 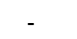 & NS \\
\hline Overall obstruction & 7 & 28 & 8 & 4.7 & $P<0.01$ \\
\hline
\end{tabular}

NS- Non significant

Table 6: Sex wise prevalence of bronchial obstruction among beauty parlour workers

\begin{tabular}{lcccccc}
\hline Parameter & \multicolumn{2}{c}{$\begin{array}{c}\text { Male } \\
(\mathbf{n = 7 0 )}\end{array}$} & & \multicolumn{2}{c}{$\begin{array}{c}\text { Female } \\
(\mathbf{n = 7 8 )}\end{array}$} & $\boldsymbol{P}$ value \\
\cline { 2 - 3 } & $\mathbf{n}$ & $\%$ & & $\mathbf{n}$ & $\%$ & \\
\hline Normal & 69 & 98.57 & & 64 & 82.05 & NS \\
Mild & 1 & 1.42 & & 13 & 16.6 & NS \\
Moderate & - & - & & 1 & 1.3 & NS \\
Overall obstruction & 1 & 1.42 & & 14 & 17.9 & $P<0.01$ \\
\hline NS- Non significant & & & & & &
\end{tabular}

\section{DISCUSSION}

In medical literature, several studies are available that describe the prevalence of respiratory morbidity and the changes occurring in spirometric lung function in workers exposed to cosmetics products. ${ }^{[17-21]}$ But studies on respiratory health of beauty parlor workers is lacking. Most of the reports available are associated with hairdressers and cosmetologists. Cosmetologists and hairdressers can be considered as a comparable group to beauty parlor workers, as they perform hair dressing to services including chemical processes such as bleaching, coloring of hair and permanent waving.

The present study shows a risk of respiratory health among beauty parlor workers compared to control group. Female workers are more prone to bronchial obstruction than male workers. The results of the present study support the other cross-sectional studies that have found increased prevalence of respiratory symptoms in hairdressers, even after adjusting for smoking. ${ }^{[22-25]}$

Even asymptomatic workers show prevalence of bronchial obstruction of $4.7 \%$, which denotes the work exposure related upper airway obstruction. Symptomatic workers also show $28 \%$ bronchial obstruction. From the prevalence of respiratory morbidity, it is clear that susceptibility to respiratory symptoms is higher among male workers than female workers. Women workers show a higher prevalence of bronchial obstruction from PEFR study, which shows that the women workers are more prone to obstruction of upper airways. Dusts and exposure to perfumes, fragrance products and other cosmetics on inhalation may cause narrowing of airways by direct action on the smooth muscle of the bronchi 
and bronchioles. Irritation of the upper respiratory tract and consequent bronchospasm may cause generalized airway obstruction.

The present study did show an association between working in the beauty parlors and respiratory symptoms along with decline in PEFR among workers. The study suggested that the workers engaged in beauty parlor have a greater possibility of developing respiratory impairment than the controls, as workers in the present study were non-smokers. It is also suggested that beauty parlor workers must undergo pre-employment and periodic medical surveillance tests. These tests will identify the susceptible workers, so that they can take adequate preventive measures as well as medication.

\section{ACKNOWLEDGMENTS}

The authors thank all the beauty parlors of Lucknow, India, for their cooperation in conducting this study. This is ITRC Communication No. 2398.

\section{REFERENCES}

1. Imbus HR. Clinical aspects of occupational medicine. In: Carl, Zenz, Bruce O, Dickerson, Edward P, Horvarth JR, editors. Occupational medicine. $1^{\text {st }}$ edn. London: Mosby; 1994. p. 3.

2. Czeslawa S, Barbara M, Jacek D, Ewa KT, Janusz M, Helen F, et al. Effect of exposure to grain dust in polish farmers: Work related symptoms and immunological response to microbial antigens associated with dust. Ann Agric Environ Med 1998;5:147-53.

3. Slater T, Bradshaw L, Fishwick D, Cheng S, Kimbell-Dunn M, Erkinjuntti- Pekkanen R, et al. Occupational respiratory symptoms in New Zealand hair dressers. Occup Med 2000;50:586-90.

4. Leino T, Tammilehto L, Luukkonen R, Nordman H. Self reported respiratory symptoms and diseases among hairdressers. Occup Environ Medicine 1997;54:452-5.

5. Osorio AM, Bernstein L, Garabrant DH, Peters JM. Investigation of lung cancer among female cosmetologists. J Occup Med 1986;28:291-5.

6. Lamba AB, Ward MH, Weeks JL, Dosemeci M. Cancer mortality patterns among hair dressers and barbers in 24 US states, 1984 to 1995. J Occup Environ Med 2001;43:250-8.

7. Meneck HR, Pike MC, Henderson BE, Jing JS. Lung cancer risk among beauticians and other female workers. J Natl Cancer Inst 1977;59:1423-5.
8. Garfinkel J, Selvin S, Brown SM. Possible increased risk of lung cancer among beauticians. J Natl Cancer Inst 1977;58:141-3.

9. Leino T, Tammilehto H, Paakkulainen H, Orjala H, Nordman H. Occurrence of asthma and chronic bronchitis among female hair dressers. J Occup Environ. Med 1997;39:534-9.

10. Renzetti A, Conrad J, Watanable S, Palmer A, Armstrong J. Thesaurosis from hair spray exposure - a non disease. Environ Res 1980;22:130-8.

11. Schwartz HJ, Arnold JL, Strohl KP. Occupational allergic rhinitis in the hair care industry: reactions to permanent wave solutions. J Occup Med 1990;32:473-5.

12. Ruppel GL. Pulmonary function testing - trends and techniques. Resp Care Clinics North Amer 1997;3:155-81.

13. McKayray T, Horvath EP. Pulmonary function testing in industry. In: Carl, Zenz, Bruce O, Dickerson, Edward P, Horvarth JR, editors. Occupational medicine. $1^{\text {st }}$ edn. London: Mosby; 1994. p. 229.

14. Samet JM. A historical and epidemiologic perspective on respiratory symptoms questionnaires. Am J Epidemiol 1978;108:435-46.

15. American Thoracic Society. Statement on standardization of spirometry. Am Rev Res Dis 1987;136:1286-96.

16. Rastogi SK, Mathur N, Clark SH. Ventilatory norms in healthy industrial male workers. Ind J Chest Dis Allied Sci 1983;25:186-95.

17. Hoppin JA, Ulmer R, London SJ. Phthalate exposure and pulmonary function. Environ. Health. Perspect 2004;112:571-4.

18. Elderling J, Linnerberg A, Durksen A, Johansen JD, Frolund L, Madsen $\mathrm{F}$, et al. Mucosal symptoms elicited by fragrance production in a population based sample in relation to atopy and bronchial hyperactivity. Clin Exp Allergy 2005;35:75-81.

19. Oie L, Hersoug LG, Madsen JO. Residential exposure to plasticizers and its possible role in the pathogenesis of asthma. Environ Health Perspect 1997;105:972- 8.

20. Hollund JA, Brock JW, Davis BJ, Baird DD. Prevalence of airway symptoms among hairdressers in Bergen, Norway. Occup Environ Med 2001;58:780-5.

21. Iwatsubo Y, Marat M, Brochard Ameille PJ, Choudat DF Conso, et al. Healthy worker effect and changes in respiratory symptoms and lung function in hair dressing apprentices. Occup Environ Med 2003;60:83140.

22. Leino T, Tammilehto L, Luukkonen R, Nordman H. Self reported respiratory symptoms and diseases among hair dressers. Occup Environ Med 1997;54:452-5.

23. Blainey A, Ollier S, Cundell D, Smith R, Davies R. Occupational asthma in a hair dressing salon. Thorax 1986;41:42-50.

24 Gowdy JM, Wagstaff MJ. Pulmonary infiltration due to aerosol thesaurosis: A survey of hair dressers. Arch Environ Health 1972;25:101-8.

25. Palmer A, Attilio D, Renzetti A, Gillam D. Respiratory diseases prevalence in cosmetologists and its relationship to aerosol sprays. Environ Res 1979;19:136-53. 